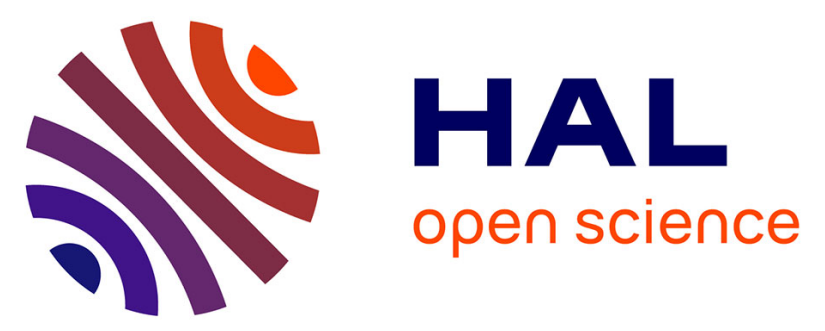

\title{
Safety enhancement by transposition of the nitration of toluene from semi-batch reactor to continuous intensified heat exchanger reactor
}

\author{
Nathalie Di Miceli Raimondi, Nelly Olivier-Maget, Nadine Gabas, Michel \\ Cabassud, Christophe Gourdon
}

\section{To cite this version:}

Nathalie Di Miceli Raimondi, Nelly Olivier-Maget, Nadine Gabas, Michel Cabassud, Christophe Gourdon. Safety enhancement by transposition of the nitration of toluene from semi-batch reactor to continuous intensified heat exchanger reactor. Chemical Engineering Research and Design, 2015, 94, pp.182-193. 10.1016/j.cherd.2014.07.029 . hal-01338167

\section{HAL Id: hal-01338167 https://hal.science/hal-01338167}

Submitted on 28 Jun 2016

HAL is a multi-disciplinary open access archive for the deposit and dissemination of scientific research documents, whether they are published or not. The documents may come from teaching and research institutions in France or abroad, or from public or private research centers.
L'archive ouverte pluridisciplinaire HAL, est destinée au dépôt et à la diffusion de documents scientifiques de niveau recherche, publiés ou non, émanant des établissements d'enseignement et de recherche français ou étrangers, des laboratoires publics ou privés. 


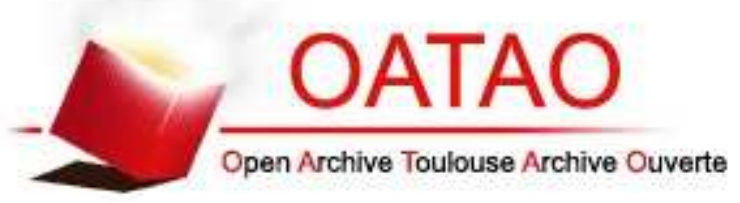

\section{Open Archive TOULOUSE Archive Ouverte (OATAO)}

OATAO is an open access repository that collects the work of Toulouse researchers and makes it freely available over the web where possible.

This is an author-deposited version published in : http://oatao.univ-toulouse.fr/ Eprints ID : 15849

To link to this article : DOI:10.1016/j.cherd.2014.07.029

URL : http://dx.doi.org/10.1016/j.cherd.2014.07.029

To cite this version : Di Miceli Raimondi, Nathalie and Olivier Maget, Nelly and Gabas, Nadine and Cabassud, Michel and Gourdon, Christophe Safety enhancement by transposition of the nitration of toluene from semi-batch reactor to continuous intensified heat exchanger reactor. (2015) Chemical Engineering Research and Design, vol. 94. pp. 182-193. ISSN 0263-8762

Any correspondence concerning this service should be sent to the repository administrator: staff-oatao@ listes-diff.inp-toulouse.fr 


\title{
Safety enhancement by transposition of the nitration of toluene from semi-batch reactor to continuous intensified heat exchanger reactor
}

\author{
N. Di Miceli Raimondi ${ }^{a, b, *}$, N. Olivier-Maget ${ }^{a, b}$, N. Gabas ${ }^{a, b}$, \\ M. Cabassud ${ }^{a, b}$, C. Gourdon ${ }^{a, b}$ \\ a Université de Toulouse, INPT, UPS, Laboratoire de Génie Chimique, 4, Allée Emile Monso, F-31030 Toulouse, France \\ b CNRS, Laboratoire de Génie Chimique, F-31030 Toulouse, France
}

\begin{abstract}
A B S T R A C T
The behavior of a continuous intensified heat exchanger (HEX) reactor in case of process failure is analyzed and compared to the behavior of a semi-continuous reactor. The nitration of toluene is considered as test reaction to identify the main failure scenarios that can lead to thermal runaway in both processes using the HAZOP method. No flow rate of process fluid and utility fluid in the continuous process. No stirring during feeding of the reactor followed by normal stirring for the semi-continuous reactor. These scenarios are simulated for both processes and the temperature profiles are observed. This study shows that the temperature is better controlled in the continuous process because of the intrinsic characteristics of the HEX reactor. In fact, this device has a low reactive volume relative to the mass of the reactor, allowing a good dissipation of the heat produced by the reaction, even in case of failure. This characteristic of the intensified reactor is confirmed by an experimental work.
\end{abstract}

Keywords: Process intensification; Heat-exchanger reactor; Nitration; Safety; Simulation; Failure scenarios

\section{Introduction}

Process intensification aims at offering drastic improvements in chemical manufacturing particularly in terms of cost, energy consumption, safety, quantity and quality of wastes. The purpose is to develop new media (ionic liquids, supercritical fluids, etc.), new methods of activation (microwaves, ultrasounds, etc.) and new technologies (microreactors, hybrid separators, etc.) to allow these improvements. One of the basic concepts of process intensification is the use of multifunctional apparatuses where more than one unit operation are performed in a unique equipment such as intensified heat exchangers (HEX) reactors (Anxionnaz et al., 2008). These apparatuses are very promising alternatives to batch or semibatch reactors mainly used in fine chemicals manufacture. Their prospects are a drastic reduction of unit size and solvent consumption while safety is increased due to their remarkable heat transfer capabilities. However, Ebrahimi et al. (2012) pointed out the fact that process intensification by miniaturization improves safety in many cases but that this trend cannot be generalized. Therefore, a safety analysis is required prior to the implementation of an intensified process based on a new technology.

The present work aims to demonstrate the intrinsically safer behavior of a HEX reactor developed by the Laboratoire de Génie Chimique (LGC - Toulouse, France) and the Boostec company specialized in the manufacture of equipments made of silicon carbide (SiC). This material presents excellent chemical resistance, high mechanical strength and stiffness, high thermal resistance and good conductivity $\left(180 \mathrm{~W} \mathrm{~m}^{-1} \mathrm{~K}^{-1}\right.$ at $20^{\circ} \mathrm{C}$ ). The performances of this device have already been demonstrated to handle exothermic reactions such as a direct fluorination (Elgue et al., 2012) and a pharmaceutical application (Despènes et al., 2012). However, its behavior in case

\footnotetext{
* Corresponding author at: Université de Toulouse, INPT, UPS, Laboratoire de Génie Chimique, 4, Allée Emile Monso, F-31030 Toulouse, France. Tel.: +33 5622589 20; fax: +33 562258891 .

E-mail address: nathalie.raimondi@iut-tlse3.fr (N. Di Miceli Raimondi).
} 


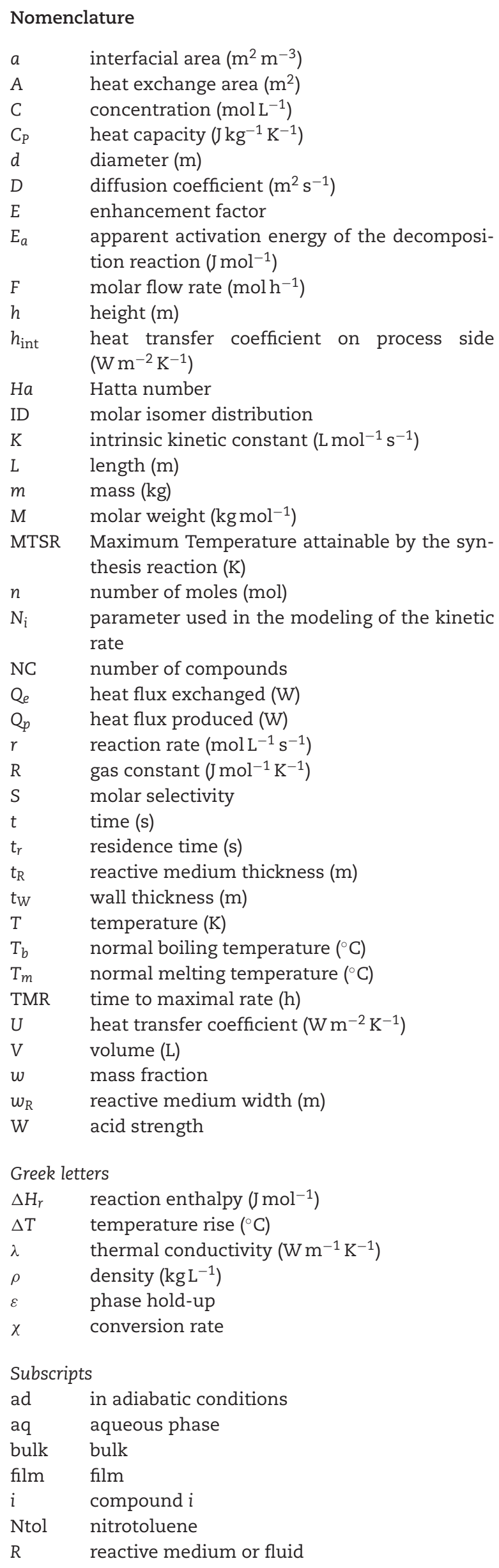

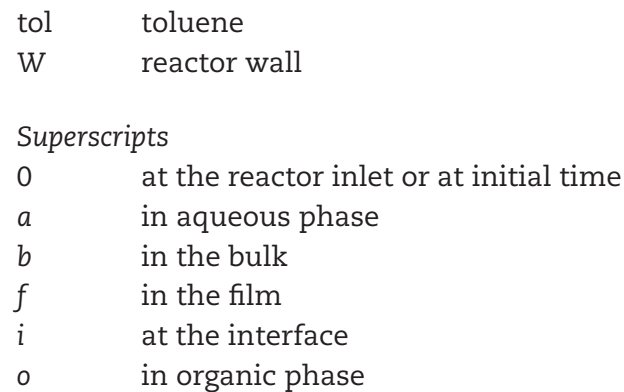

of failure has not been investigated yet. In this context, the nitration of toluene is considered as test reaction. This is a liquid-liquid reaction that presents high risk of thermal runaway due to its exothermicity and the low decomposition temperature of nitro compounds (Chen and Wu, 1996). Aromatic nitration is an intermediate reaction for the production of many compounds such as pharmaceuticals, dyes, pesticides, explosives. At the industrial scale, this reaction is mostly operated in batch or semi-batch reactors (Booth, 2000; Dugal, 2005). It has been used in several works to demonstrate the capabilities of technologies such as micro and millistructured HEX reactors (Burns and Ramshaw, 2002; Henke and Winterbauer, 2005; Halder et al., 2007; Rusli et al., 2013).

In the present work, a safety analysis is conducted to compare the risks associated to the implementation of the nitration of toluene in a semi-batch reactor and in an intensified HEX reactor. For that purpose, further to the reaction description and the presentation of the continuous process, risk assessment by HAZOP method is carried out for both processes in order to identify the failures that can cause the most serious damages. Then, critical scenarios are simulated to observe the temperature increase in both reactors in case of major failures. The inherently safer design of the SiC intensified HEX reactor is then confirmed by experiments in faulty mode.

\section{Nitration of toluene}

\subsection{Reaction description}

The nitration of toluene is performed with nitric acid in presence of sulfuric acid and water. This acid mixture is the most common nitrating system currently adopted in chemical industry (Miller et al., 1964; Harris, 1976). The main reaction is the mononitration characterized by a heat of reaction $\Delta H_{r}$ of $-125 \mathrm{~kJ} \mathrm{~mol}^{-1}$ (Chen and Wu, 1996):

$\mathrm{C}_{7} \mathrm{H}_{8}+\mathrm{HNO}_{3} \rightarrow \mathrm{C}_{7} \mathrm{H}_{7} \mathrm{NO}_{2}+\mathrm{H}_{2} \mathrm{O}$

Nitration kinetics and selectivity strongly depend on the sulfuric acid strength $\mathrm{W}$ defined as follows (Zaldivar et al., 1995):

$\mathrm{W}=\frac{w_{\mathrm{H}_{2} \mathrm{SO}_{4}}^{a}}{w_{\mathrm{H}_{2} \mathrm{SO}_{4}}^{a}+w_{\mathrm{H}_{2} \mathrm{O}}^{a}}$

where $w_{\mathrm{H}_{2} \mathrm{SO}_{4}}^{a}$ and $w_{\mathrm{H}_{2} \mathrm{O}}^{a}$ are the mass fractions of sulfuric acid and water in the aqueous phase respectively. A high sulfuric acid strength favors conversion rate but degrades selectivity. Indeed, the dinitration of toluene significantly occurs from 
Table 1 - Physical properties of the compounds.

\begin{tabular}{|c|c|c|c|c|c|}
\hline Component & CAS number & $M\left(\mathrm{~g} \mathrm{~mol}^{-1}\right)$ & $\mathrm{T}_{m}\left({ }^{\circ} \mathrm{C}\right)$ & $\mathrm{T}_{b}\left({ }^{\circ} \mathrm{C}\right)$ & $C_{P}\left(\mathrm{Jkg}^{-1} \mathrm{~K}^{-1}\right)$ \\
\hline Water & $7732-18-5$ & 18.02 & 0 & 100 & $4183^{a}$ \\
\hline Nitric acid & $7697-37-2$ & 63.01 & -42 & 83 & $1744^{\mathrm{a}}$ \\
\hline Sulfuric acid & $7664-93-9$ & 98.08 & 10 & 337 & $1416^{a}$ \\
\hline Toluene & $108-88-3$ & 92.14 & -95 & 111 & $1705^{\mathrm{a}}$ \\
\hline 2-Nitrotoluene & $88-72-2$ & 137.14 & -2 & 223 & $1476^{b}$ \\
\hline 3-Nitrotoluene & $99-08-1$ & 137.14 & 16 & 231 & $1473^{b}$ \\
\hline 4-Nitrotoluene & $99-99-0$ & 137.14 & 52 & 238 & $1256^{\mathrm{d}}$ \\
\hline 2,4-Dinitrotoluene & $121-14-2$ & 182.13 & 70 & 221 & $1400^{\mathrm{d}, \mathrm{c}}$ \\
\hline 2,6-Dinitrotoluene & $606-20-2$ & 182.13 & 65 & 192 & $1208^{\mathrm{d}, \mathrm{b}}$ \\
\hline $\mathrm{SiC}$ & $409-21-2$ & 40.10 & 2557 & - & $668^{\mathrm{d}}$ \\
\hline \multicolumn{6}{|c|}{ Source: NIST (2013) and Haynes (2013). } \\
\hline \multicolumn{6}{|l|}{ a Data at $25^{\circ} \mathrm{C}$. } \\
\hline \multicolumn{6}{|l|}{ b Data at $30^{\circ} \mathrm{C}$} \\
\hline \multicolumn{6}{|l|}{ c Data at $52^{\circ} \mathrm{C}$. } \\
\hline d Data for stable ar & able crystal form. & & & & \\
\hline
\end{tabular}

$\mathrm{W}=0.8$. The trinitration occurs in anhydrous medium $(\mathrm{W}=1)$. As the acid strength, temperature also promotes the formation of byproducts (Franck and Stadelhofer, 1987; Booth, 2000). Hence the mononitration of toluene is generally carried out at $30-45^{\circ} \mathrm{C}$ with acid strength slightly lower than 0.8 . The impact of acid strength on nitration kinetic makes possible the inhibition of the reactions by dilution. Therefore nitration can be quenched by adding water to the reactive medium: this method is adopted in order to collect and analyze samples at the reactor output. Gas chromatography technique with an internal standardization method is used to measure the composition of the organic phase using a $25 \mathrm{~m} \mathrm{HP}-1$ non-polar capillary column and an ionization flame detector (detection of toluene, mononitrotoluenes and dinitrotoluenes).

The physical properties of the compounds used in the present study are given in Table 1 (molar weight $M$, normal melting temperature $T_{m}$ and boiling temperature $T_{b}$ and heat capacity $\left.C_{P}\right)$.

\subsection{Risk assessment}

The mononitration of toluene is highly exothermic. Therefore, its processing requires a control of the temperature to manage the risk of thermal runaway due to the low decomposition temperature of nitro compounds. Indeed, Chen and Wu (1996) studied the thermal stability of all the compounds by differential scanning calorimetry. They observed that the decomposition of nitric acid was beginning to $120^{\circ} \mathrm{C}$, and about $240^{\circ} \mathrm{C}$ for toluene and mononitrated compounds. Therefore reaction mixture has to be kept below $120^{\circ} \mathrm{C}$.
Chen and Wu (1996) also measured the self-heat rate of the reaction mixture as a function of temperature using an accelerating rate calorimeter to access to the time to maximal rate, TMR (Townsend and Tou, 1980). This data corresponds to the amount of time before a reaction gets out of control in adiabatic conditions. For an initial temperature of $140^{\circ} \mathrm{C}$, TMR is about $2 \mathrm{~h} ; 20 \mathrm{~min}$ at $160^{\circ} \mathrm{C} ; 2 \mathrm{~min}$ at $180^{\circ} \mathrm{C}$. At industrial scale, a reaction is supposed to be performed under safe conditions if TMR is higher than $8 \mathrm{~h}$ (Stoessel, 2008).

\section{Intensified continuous process}

\subsection{SiC heat exchanger reactor}

The device used in this work is designed as a millistructured plate heat exchanger with a regular series of plates made of silicon carbide $(\mathrm{SiC})$ where process and utility fluids circulate (Fig. 1). The thickness of a plate of $\mathrm{SiC}$ is $6 \mathrm{~mm}$. The structure is held between two end plates of stainless steel. Its behavior can be assimilated to a cross-flow heat exchanger. The nitration of toluene is carried out in this device composed of 3 plates where the process fluid circulates (process plates) and 4 utility plates. The whole reactor weighs $16 \mathrm{~kg}$ with approximately $3 \mathrm{~kg}$ of $\mathrm{SiC}$.

The process fluid flows in a square section meandering channel of $2 \mathrm{~mm}$ in depth and about $3 \mathrm{~m}$ long by plate. The process volume by plate is $11.3 \mathrm{~mL}$ ( $34 \mathrm{~mL}$ for the whole reactor). The ratio between the surface of the channel and its volume is $2000 \mathrm{~m}^{2} \mathrm{~m}^{-3}$. The utility fluid flows in 15 parallel square
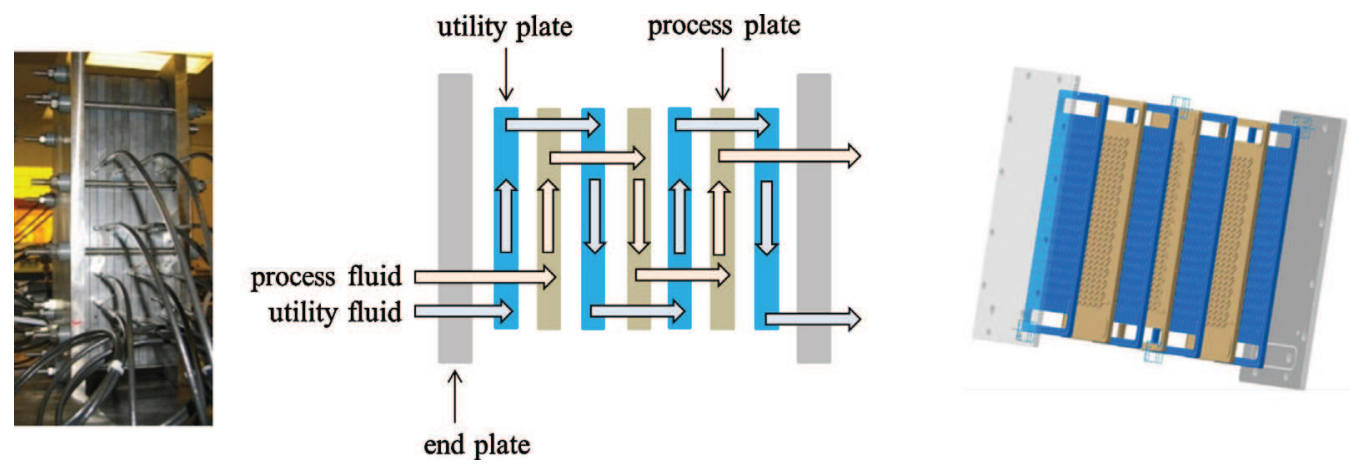

Fig. 1 - SiC HEX reactor structure. 


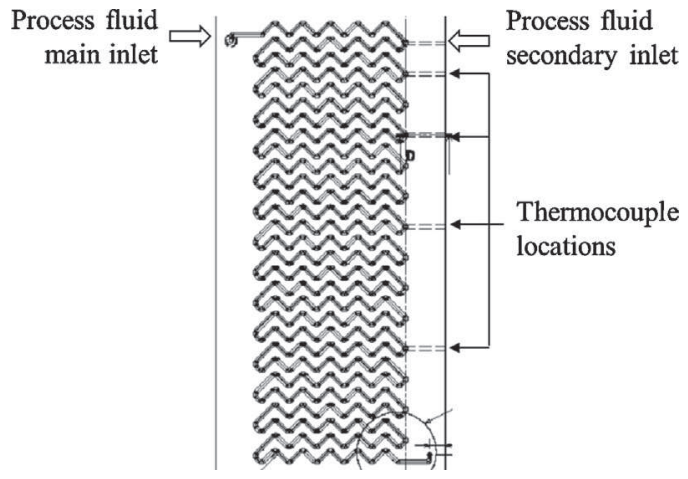

Fig. 2 - Pattern of a process plate.

section meandering channels by plate of $2 \mathrm{~mm}$ in depth. All the channels are engraved in the $\mathrm{SiC}$ plates.

Circular subchannels of $2 \mathrm{~mm}$ diameter are drilled in the thickness of the process plates. They lead to the main channel to enable injection of fluids or insertion of thermocouples. The thermocouples are set up in order to be located at the channel surface for non-intrusive temperature measurements. The configuration illustrated in Fig. 2 corresponds to the first process plate: the aqueous phase is introduced at the main input and toluene is injected through the secondary input.

Previous works studied the hydraulic behavior of fluids in meandering ducts or channels (Joseph et al., 1975; Ligrani and Niver, 1988; Fellouah et al., 2006). In the case of one-phase flow, they showed that despite low Reynolds number due to low velocity and small channel size, vortices can appear in the channel bends. These vortices avoid pure laminar flow and allow an enhancement of mixing (Jiang et al., 2004; Anxionnaz et al., 2013) and heat transfer (Rush et al., 1999; Chandratilleke and Nursubyakto, 2003). This particular hydrodynamic behavior in the reactor and the $\mathrm{SiC}$ properties allows to obtain heat transfer coefficients up to $10000 \mathrm{~W} \mathrm{~m}^{-2} \mathrm{~K}^{-1}$ (Despènes et al., 2012).

\subsection{Experimental setup}

The experimental setup presented in Fig. 3 is composed of 4 lines:

- The feed line of the aqueous phase is composed of a gear pump (flow rate is controlled by the motor frequency), a flow meter, temperature and pressure sensors and a pressure safety valve calibrated at 16 bar. This line can be fed by two different tanks. The first one contains water for start and stop operations (V-101). The second one contains the acid mixture composed of nitric acid, sulfuric acid and water (V102). For safety reasons, it is possible to flush the reactor with water from the utility network (F-105) in order to avoid a stagnation of the reactive medium in the reactor in case of pump failure.

- The feed line of toluene is composed of a tank (V-103), a gear pump, a flow meter, temperature and pressure sensors and a pressure safety valve calibrated at 16 bar.

- The output line is composed of a valve to collect samples and a coaxial tube in which circulates glycol/water mixture (F-106) at $5{ }^{\circ} \mathrm{C}$ in order to drastically decrease the temperature of the outlet fluid in case of incomplete conversion rate in the reactor. The outlet tank V-104 is stirred and partly filled with water before operation to quench the reaction.

- The utility line is composed of a flow meter and temperature sensors. The utility fluid is water. The temperature of the fluid is controlled using a heated circulating bath.

13 thermocouples are inserted into the reactor in order to measure the temperature of the process fluid all along the channel.

\subsection{Experiments in normal operation mode}

The nitration of toluene is carried out under the following operating conditions:

- Toluene is in excess compared to nitric acid with a molar ratio of $1.5 / 1$ in order to avoid the crystallization of 4nitrotoluene $\left(T_{m}=52^{\circ} \mathrm{C}\right.$, see Table 1$)$.

- Nitric acid concentration in aqueous phase is $4 \mathrm{~mol} \mathrm{~L}^{-1}$.

- Acid strength ranges from 0.75 to 0.80 .

- Toluene flow rate ranges from 0.9 to $1.1 \mathrm{~L} \mathrm{~h}^{-1}$.

- Acid mixture flow rate ranges from 1.4 to $1.8 \mathrm{~L} \mathrm{~h}^{-1}$.

- Utility fluid temperature ranges from 23 to $35^{\circ} \mathrm{C}$.

- Utility fluid flow rate is $80 \mathrm{~L} \mathrm{~h}^{-1}$.

Table 2 presents the results obtained for different operating conditions (acid strength $\mathrm{W}$, temperature of the utility fluid $T$, residence time $t_{r}$ which depends on the total flow rate). Conversion rate $\chi$ corresponds to the nitric acid conversion rate (reactant in default) obtained from Eq. (3). Selectivity $S$ is defined as the ratio between the sum of the molar outlet flow rates of the three mononitrotoluene isomers and the molar flow rate of toluene converted (Eq. (4)). The molar

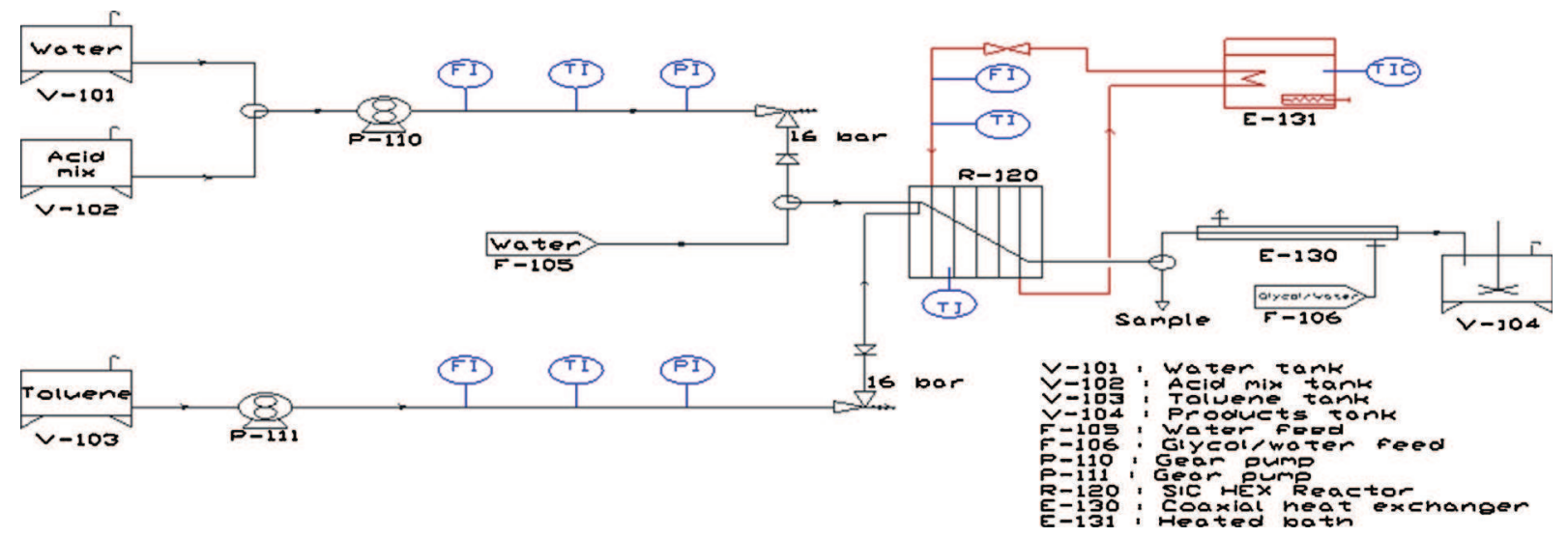

Fig. 3 - Experimental setup for the nitration of toluene in the continuous process. 
Table 2 - Experimental results of the nitration of toluene obtained in the SiC HEX reactor.

\begin{tabular}{|c|c|c|c|c|c|c|c|}
\hline \multirow[t]{2}{*}{ W } & \multirow[t]{2}{*}{$\mathrm{T}\left({ }^{\circ} \mathrm{C}\right)$} & \multirow[t]{2}{*}{$t_{r}(\mathrm{~s})$} & \multirow[t]{2}{*}{$\chi(\%)$} & \multirow[t]{2}{*}{$\mathrm{S}(\%)$} & \multicolumn{3}{|c|}{ ID (\%) } \\
\hline & & & & & 2-Nitrotoluene & 3-Nitrotoluene & 4-Nitrotoluene \\
\hline 0.75 & 23 & 40 & 8.5 & 98.0 & 57.6 & 4.0 & 38.5 \\
\hline 0.75 & 23 & 50 & 9.2 & 98.0 & 57.7 & 4.0 & 38.4 \\
\hline 0.75 & 30 & 40 & 9.9 & 98.2 & 57.5 & 4.2 & 38.3 \\
\hline 0.75 & 30 & 50 & 9.3 & 98.3 & 57.4 & 4.2 & 38.5 \\
\hline 0.75 & 35 & 40 & 11.9 & 98.6 & 57.6 & 4.1 & 38.4 \\
\hline 0.75 & 35 & 50 & 13.9 & 98.6 & 57.6 & 4.2 & 38.2 \\
\hline 0.80 & 28 & 40 & 26.7 & 94.8 & 55.9 & 4.1 & 40.0 \\
\hline 0.80 & 27 & 50 & 33.7 & 95.1 & 54.8 & 4.6 & 40.5 \\
\hline
\end{tabular}

isomer distribution ID of mononitrated products is obtained by Eq. (5):

$$
\begin{gathered}
\chi=\frac{F_{\mathrm{HNO}_{3}}^{\text {in }}-F_{\mathrm{HNO}_{3}}^{\text {out }}}{F_{\mathrm{HNO}_{3}}^{\text {in }}} \\
\mathrm{S}=\frac{F_{2 \mathrm{Ntol}}^{\text {out }}+F_{3 \mathrm{Ntol}}^{\text {out }}+F_{4 \mathrm{Ntol}}^{\text {out }}}{F_{\text {tol }}^{\text {in }}-F_{\text {tol }}^{\text {out }}} \\
\mathrm{ID}_{i}=\frac{F_{i}^{\text {out }}}{F_{2 \mathrm{Ntol}}^{\text {out }}+F_{3 \mathrm{Ntol}}^{\text {out }}+F_{4 \mathrm{Ntol}}^{\text {out }}}
\end{gathered}
$$

For $\mathrm{W}=0.75$, the conversion rate increases from about $8.5 \%$ to $14 \%$ when the temperature is increased from $23^{\circ} \mathrm{C}$ to $35^{\circ} \mathrm{C}$. Selectivity is about $98 \%$. As expected, conversion rate and selectivity are highly sensitive to acid strength. For $\mathrm{W}=0.80$ at $28^{\circ} \mathrm{C}$, conversion rate is about $30 \%$ for a selectivity of $95 \%$. The molar isomer distribution for the mononitration is consistent with literature. Indeed, Harris (1976) and Molga et al. (1993) obtained $55-65 \%$ of 2-nitrotoluene, 3.5-4.5\% of 3-nitrotoluene and $34-40 \%$ of 4 -nitrotoluene.These experiments demonstrate the capability of the device to handle the nitration under typical operating conditions ( $\mathrm{W}=0.8, \mathrm{~T}=30^{\circ} \mathrm{C}$ ). It is possible to achieve conversion rates of $30 \%$ with less than 1 min of residence time. It has to be mentioned that the residence time can simply be increased by adding plates to the HEX reactor.

\section{Transposition from semi-batch to continuous process: impact on safety}

\subsection{Nitration of toluene in semi-batch process}

In order to control the temperature rise due to the exothermicity of the reaction, the nitration of toluene is generally carried out in a fed batch (semi-batch) reactor. The reactor is initially filled with toluene and the acid mixture is fed. The total operation time is between 2 and $4 \mathrm{~h}$. It takes into account the feeding time of the acid mixture, around 1.5-3 h (Rusli et al., 2013; D'Angelo et al., 2003). D'Angelo et al. (2003) carried out the reaction at a laboratory scale in a jacketed reactor of $1.5 \mathrm{~L}$ where the monofluid is a glycol-water mixture. The experimental setup is given in Fig. 4. The monofluid temperature is controlled using a heating-cooling system composed of an electrical resistance and two plate heat-exchangers (the first one uses water at $15^{\circ} \mathrm{C}$, the second one a glycol-water mixture at $-10^{\circ} \mathrm{C}$ ). The operating conditions are described in Table 3.

\subsection{Risk assessment by HAZOP method}

The thermal runaway risk for the process considered in this work can be evaluated according to two criteria:

- The adiabatic temperature rise $\Delta \mathrm{T}_{\mathrm{ad}}$ which corresponds to the temperature rise at total conversion rate in adiabatic conditions:

$$
\Delta \mathrm{T}_{\mathrm{ad}}=\frac{-\Delta \mathrm{H}_{\mathrm{r}} \mathrm{F}_{\text {toluene }}^{0}}{\sum_{\mathrm{i}=1}^{N C} F_{i}^{0} C_{P, i} \mathrm{M}_{\mathrm{i}}}
$$

- The time to maximum rate (TMR) evaluated at the maximum temperature attainable by the synthesis reaction (MTSR) (Eq. (7)). This temperature is reached when the desired chemical reaction is carried out under adiabatic conditions, starting at the process temperature $\mathrm{T}$ (Eq. (8)).

$$
\mathrm{TMR}=\frac{R \cdot \mathrm{MTSR}^{2}}{\left(\frac{d T}{d t}\right) \cdot E_{a}}
$$

$\operatorname{MTSR}=\mathrm{T}+\Delta \mathrm{T}_{\mathrm{ad}}$

$E_{a}$ is the apparent activation energy of the decomposition reaction, assuming a zero-order kinetic, and $(d T / d t)$ is the selfheat rate due to this reaction. $R$ is the gas constant. Chen and $\mathrm{Wu}$ (1996) determined the evolution of TMR as a function of temperature. Considering the operating conditions described before, the evaluation of the adiabatic temperature rise gives $\Delta \mathrm{T}_{\mathrm{ad}}=120^{\circ} \mathrm{C}$. It corresponds to $\mathrm{TMR}=30 \mathrm{~min}$ with reference to Chen and $\mathrm{Wu}$ (1996) data, which classified this reaction as highly critical regarding the risk of thermal runaway (Stoessel, 2008).

In order to compare the dangerousness of the semi-batch and the continuous processes, risk assessment by the HAZOP method was carried out (Di Miceli Raimondi et al., 2009).

\section{Table 3 - Operating conditions for the nitration of}

toluene in a laboratory scale semi-batch reactor.

\begin{tabular}{ll} 
Initial acid strength (\%) & 80 \\
Temperature $\left({ }^{\circ} \mathrm{C}\right)$ & 30 \\
Initial mass of toluene $(\mathrm{g})$ & 260 \\
Total mass of acid mixture injected $(\mathrm{g})$ & 767 \\
Mass composition of the acid mixture $(\%)$ & $\mathrm{HNO}_{3} / \mathrm{H}_{2} \mathrm{SO}_{4} / \mathrm{H}_{2} \mathrm{O}$ : \\
& $23.2 / 61.4 / 15.4$ \\
Feeding time & $2 \mathrm{~h} 52$ \\
Total operation time & $4 \mathrm{~h}$ \\
\hline Source: D'Angelo et al. (2003). &
\end{tabular}

Temperature $\left({ }^{\circ} \mathrm{C}\right)$

Total mass of acid mixture injected (g)

Feeding time

Source: D'Angelo et al. (2003). 


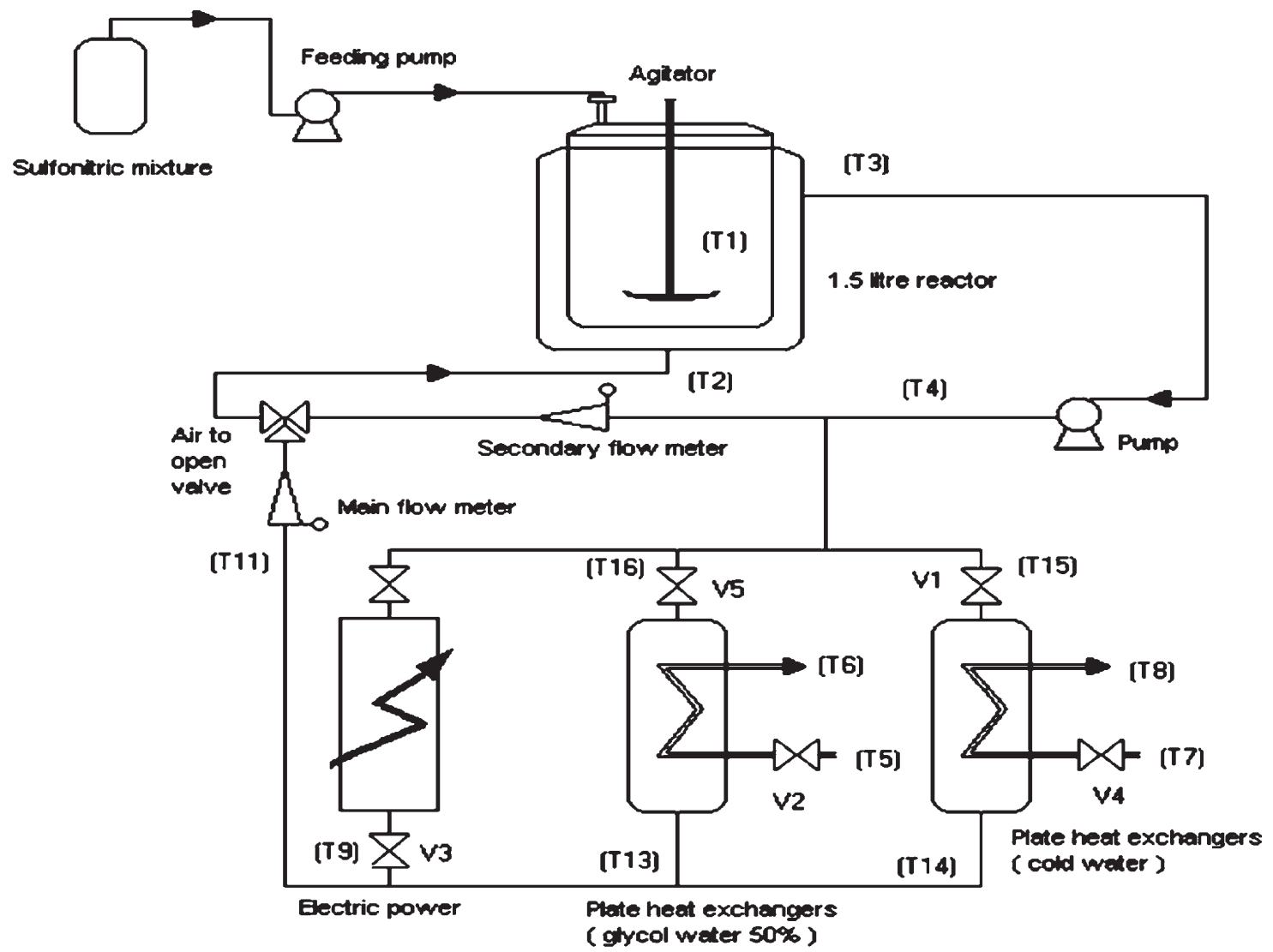

Fig. 4 - Semi-batch reactor - experimental setup at laboratory scale.

Source: D'Angelo et al. (2003).

This method considers the potential deviations of each operating parameter (temperature, pressure, flow rate, etc.) and study their causes and consequences (Dunjo et al., 2010). Table 4 describes the deviations identified for both processes that lead to thermal runaway. It appears that the risk of thermal runaway is not negligible in the continuous process. However, this method does not take into account the characteristics of the reactors (notably the ratio between the mass of the reactor and the mass of the reactive medium). Simulations are carried out to estimate the value of the temperature rise and the temperature increasing rate in case of failure.

\subsection{Simulations of severe failure scenarios}

\subsubsection{Description of the scenarios}

Among the scenarios presented in Table 4, the ones leading to the most dramatic consequences have been simulated.

- For the semi-batch process, failure 3 is simulated: LESS temperature in the reactor while normal feeding (for instance no stirring so low interfacial area) followed by MORE temperature in the reactor (return to normal stirring condition after the feeding is completed) caused by NO utility flow rate and MORE reactant in the reactor. This scenario corresponds to

\section{Table 4 - Failures that lead to thermal runway (HAZOP method).}

Semi-batch process (fed stirred tank reactor)

Failure 1: MORE reactant feeding flow rate

- Example of cause: feeding pump failure

Consequence: increase of the heat production by the reaction

leading to a rise of the fluid temperature

Failure 2: MORE temperature in the reactor

- Example of cause: failure of the temperature regulation system

Consequence: rise of the fluid temperature

\section{Failure 3: LESS temperature in the reactor}

Example of cause: less or no stirring

- Consequence: decrease of the reaction rate leading to an

accumulation of the reactants in the reactor that can be dramatic in

case of return to normal operating conditions
Continuous process (heat-exchanger reactor)

Failure 1: NO utility flow rate

- Example of cause: pipe rupture

- Consequence: degradation of heat transfer

(utility side) leading to a rise of the fluid temperature

Failure 2: NO process flow rate

Example of cause: both feed line pumps failure - Consequence: degradation of heat transfer (process side) leading to a rise of the fluid temperature

Failure 3: MORE temperature in the reactor - Example of cause: thermostated bath pump break down

- Consequence: rise of the fluid temperature 
Table 5 - Semi-batch and continuous processes considered for the simulation of the failure scenario.

$\begin{array}{ll}\text { Process } & \\ \text { Reactor geometry } & \\ \text { Heat transfer coefficients } & \end{array}$

a batch reactor in adiabatic condition (no heat is transferred to the stagnant utility fluid).

- For the continuous process, failures 2 and 3 are simulated simultaneously: MORE temperature in the reactor caused by NO utility flow rate and NO process flow rate. Therefore the reactor can also be assimilated to a batch reactor in adiabatic condition (no heat is transferred to the stagnant utility fluid).

In order to compare both processes, the semi-batch reactor volume is calculated to obtain the same productivity than in the continuous process, i.e. $2.4 \mathrm{~L} \mathrm{~h}^{-1}$ of total flow rate $\left(0.9 \mathrm{~L} \mathrm{~h}^{-1}\right.$ in toluene and $1.4 \mathrm{~L} \mathrm{~h}^{-1}$ in acid mixture). Typical operation time in fed batch for the nitration of toluene is about $3 \mathrm{~h}$ (Rusli et al., 2013): hence the reactive medium volume of the semi-batch reactor is $7.1 \mathrm{~L}$. The reactor wall for both processes is supposed made of $\mathrm{SiC}$ in order to consider the same thermal characteristics of the material $\left(\lambda \mathrm{W}=180 \mathrm{~W} \mathrm{~m}^{-1} \mathrm{~K}^{-1}\right.$; $\left.C_{P, W}=668 \mathrm{~J} \mathrm{~kg}^{-1} \mathrm{~K}^{-1} ; \rho_{\mathrm{W}}=3.16 \mathrm{~kg} \mathrm{~L}^{-1}\right)$. Table 5 illustrates the configuration and parameters of both scenarios. It has to be mentioned that the hypotheses for the simulations are unfavorable for the continuous process (overestimation of the heat produced and underestimation of the heat exchanged) compared to the semi-batch process. The mass of the wall in the continuous process is underestimated compared to the total mass of the HEX reactor. Indeed, only the walls between the utility fluid and the process fluid are taken into account. Therefore the exchange area $A$ is also underestimated (half of the total area is considered). This hypothesis tends to minimize the heat flux transferred to the reactor wall in order to overestimate the risk of thermal runaway for this process configuration.

Heat transfer coefficient estimation is based on the following assumptions:

- For both technologies, it is assumed that heat transfer between the liquid phases is not limiting.
Semi-batch reactor: the heat transfer coefficient $h_{\text {int }}$ on process side is $1000 \mathrm{~W} \mathrm{~m}^{-2} \mathrm{~K}^{-1}$. It corresponds to a typical value for small volume stirred tank. $U$ is calculated considering the resistance to transfer in the fluid and the wall:

$U=\left(\frac{1}{h_{\text {int }}}+\frac{t_{W}}{\lambda_{W}}\right)^{-1}$

- HEX reactor: in this failure scenario, process fluid is stagnant. Therefore heat transfer is supposed to occur by pure conduction. This hypothesis leads to the following equation:

$U=\left(\frac{t_{R}}{2 \lambda_{R}}+\frac{t_{W}}{\lambda_{W}}\right)^{-1}$

The thermal conductivity of the fluid is chosen low, equals to $0.1 \mathrm{~W} \mathrm{~m}^{-1} \mathrm{~K}^{-1}$ which corresponds to typical value of conductivity in organic phase (toluene: $\lambda=0.1 \mathrm{~W} \mathrm{~m}^{-1} \mathrm{~K}^{-1}$ at $25^{\circ} \mathrm{C}$ ). Aqueous phase is generally characterized by higher thermal conductivity (water: $\lambda=0.6 \mathrm{~W} \mathrm{~m}^{-1} \mathrm{~K}^{-1}$ at $25^{\circ} \mathrm{C}$ ).

Mass transfer coefficient estimation is based on the following assumptions:

- The interfacial area is calculated for droplets of organic phase of $1 \mathrm{~mm}$ diameter. In micro and millichannels, for droplets generated in a T-junction (equivalent to the configuration used in the HEX reactor), their diameter is generally limited by the diameter of the injection channel $(2 \mathrm{~mm}$ in the present work) as observed by Garstecki et al. (2006) and Gupta et al. (2013). A droplet diameter twice smaller than the injection channel is considered in this study to increase the toluene transfer and so the heat production in the continuous process. For the semi-batch process, this hypothesis tends to minimize the mass flux since droplets with diameter smaller than $100 \mu \mathrm{m}$ can be generated in stirred contactors (Fernandes and Sharma, 1967).

Mass transfer coefficient $k_{L}$ is obtained from typical values for stirred contactors (Fernandes and Sharma, 1967) 
and millichannels (Ghaini et al. (2010) obtained $k_{L} a$ values of about $1 \mathrm{~s}^{-1}$ in $1 \mathrm{~mm}$ diameter capillaries). It should be noted that the coefficient $k_{L}$ a considered for the continuous process is large in relation to the scenario imposing a stagnant process fluid. Indeed, a phenomenon of settling can occur, thereby reducing the interfacial area between the two phases. The progress of the reaction and therefore the temperature rise are overestimated in this scenario.

- Diffusion coefficients of toluene and nitric acid in aqueous phase are constant. The values used for the simulations are extrapolated from Zaldivar et al. (1995) and Yeh and Wills (1971) works.

\subsubsection{Mathematical modeling}

The mathematical model is based on the equations described afterwards. They are explicitly integrated over time according to a first-order accurate algorithm.

4.3.2.1. Material balances. It is assumed that the nitration of toluene is irreversible and occurs in the aqueous phase (Zaldivar et al., 1996). Reactants consumption depends on the intrinsic kinetic rate and mass transfer rate of toluene from the organic phase to the aqueous phase. Mass transfer estimation is based on the film theory (Trambouze and Euzen, 2002). The enhancement of mass transfer by the reaction in the film is taken into account by introducing the enhancement factor $E$ linked to the Hatta number $\mathrm{Ha}$ (see Appendix A). The solubility of toluene in aqueous phase is very low so that mass transfer limitations in the organic phase can be neglected (Levenspiel, 1999). Indeed, the model developed by Zaldivar et al. (1995) gives $C_{\text {tol }}^{a, i} \sim 0.01 C_{\text {tol }}^{o}$, where $C_{\text {tol }}^{a, i}$ is the concentration of toluene at the interface of the aqueous phase and $C_{\text {tol }}^{o}$ the concentration of toluene in organic phase. Material balances in each phase are expressed as follows:

Partial molar balances in toluene:

Organic phase:

$\frac{d n_{\text {tol }}^{o}}{d t}=-k_{L} a E\left(C_{\text {tol }}^{a, i}-C_{\text {tol }}^{a, b}\right) V_{R}$

Aqueous phase:

$\frac{d n_{\text {tol }}^{a}}{d t}=k_{L} a E\left(C_{\text {tol }}^{a, i}-C_{\text {tol }}^{a, b}\right) V_{R}-r_{\text {film }} V_{\text {film }}-r_{\text {bulk }} V_{\text {bulk }}$

Partial molar balances in nitric acid:

Organic phase:

$$
\frac{d n_{\mathrm{HNO}_{3}}^{\circ}}{d t}=0
$$

Aqueous phase:

$$
\frac{d n_{\mathrm{HNO}_{3}}^{a}}{d t}=-r_{\text {film }} \mathrm{V}_{\text {film }}-r_{\text {bulk }} \mathrm{V}_{\text {bulk }}
$$

Partial molar balances in water: Organic phase:

$$
\frac{d n_{\mathrm{H}_{2} \mathrm{O}}^{o}}{d t}=0
$$

Aqueous phase:

$$
\frac{d n_{\mathrm{H}_{2} \mathrm{O}}^{a}}{d t}=r_{\text {film }} \mathrm{V}_{\text {film }}+r_{\text {bulk }} \mathrm{V}_{\text {bulk }}
$$

Partial molar balances in sulfuric acid: Organic phase:

$\frac{d n_{\mathrm{H}_{2} \mathrm{SO}_{4}}^{\mathrm{O}}}{\mathrm{dt}}=0$

Aqueous phase:

$\frac{d n_{\mathrm{H}_{2} \mathrm{SO}_{4}}^{a}}{d \mathrm{t}}=0$

Partial molar balances in nitrotoluene: Organic phase:

$\frac{d n_{\mathrm{Ntol}}^{o}}{d t}=r_{\text {film }} V_{\text {film }}+r_{\text {bulk }} V_{\text {bulk }}$

Aqueous phase:

$\frac{d n_{\mathrm{Ntol}}^{a}}{d t}=0$

where $n$ is the number of moles and $C$ the concentration. Only the mononitration is considered since the dinitration is not significant for acid strength up to $80 \%$. The mass transfer driving force corresponds to the difference between the toluene concentrations at the interface and in the bulk in the aqueous phase, $C_{\text {tol }}^{a, i}$ and $C_{\text {tol }}^{a, b}$ respectively. $r$ is the reaction rate. $V_{\text {film }}$ and $V_{\text {bulk }}$ stand for the volumes of the film and of the bulk in the aqueous phase respectively. They are related to the volume of aqueous phase $\mathrm{V}_{\mathrm{aq}}$ by the following equations:

$V_{\text {film }}=V_{\text {aq }} \frac{a D_{\text {tol }}^{a}}{\varepsilon_{\text {aq }} k_{\mathrm{L}}}$
$V_{\text {bulk }}=V_{\text {aq }}-V_{\text {film }}$

$\varepsilon_{a q}$ is the aqueous phase hold-up, equal to 0.6 in the simulations. The reaction in the film is taken into account. The reaction rates are estimated using the following equations:

$$
\begin{aligned}
& r_{\text {film }}=K C_{\text {tol }}^{a, f} C_{\mathrm{HNO}_{3}}^{a} \\
& C_{\text {tol }}^{a, f}=\frac{\left(C_{\text {tol }}^{a, i}+C_{\text {tol }}^{a, b}\right)}{2} \\
& r_{\text {bulk }}=K C_{\text {tol }}^{a, b} C_{\mathrm{HNO}_{3}}^{a}
\end{aligned}
$$

The concentration of toluene in the film $C_{\text {tol }}^{a, f}$ corresponds to a mean value calculated from the concentrations at the interface and in the bulk. The intrinsic kinetic constant $\mathrm{K}$ and $C_{\text {tol }}^{a, i}$ are obtained from the model proposed by Zaldivar et al. (1995), validated by experiments in semi-batch reactor (D'Angelo et al., 2003). The concentration of nitric acid is supposed homogeneous in the whole aqueous phase. This hypothesis is justified in Appendix A.1. The concentration of toluene at the interface is calculated from the concentration of toluene in the organic phase (supposed homogeneous) and the equilibrium constant obtained from the model of Zaldivar et al. (1995). The estimation of the enhancement factor $E$ and the concentration of toluene in the bulk depend on the reaction regime. Their expressions are given in Appendix A.

4.3.2.2. Thermal balances. Heat transfer resistance at the liquid-liquid interface is neglected. Hence it is assumed that the temperature in the fluid is uniform. The heat capacity 
Table 6 - Initial composition of each phase in molar fraction.

\begin{tabular}{lcc} 
Component & Aqueous phase & Organic phase \\
\hline Toluene & 0.00 & 1.00 \\
Nitric acid & 0.13 & 0.00 \\
Water & 0.50 & 0.00 \\
Sulfuric acid & 0.37 & 0.00 \\
Nitrotoluene & 0.00 & 0.00 \\
\hline
\end{tabular}

of the process fluid is calculated from the heat capacity of the compounds given in Table 1 (influence of temperature neglected). Enthalpies of mixing are neglected.

Thermal balances in the process fluid and in the reactor wall are given by the following equations:

$$
\begin{aligned}
& \sum_{i=1}^{\mathrm{NC}}\left(m_{\mathrm{i}} C_{P, \mathrm{i}}\right) \frac{d \mathrm{~T}_{\mathrm{R}}}{d \mathrm{t}}-\mathrm{Q}_{p}+\mathrm{Q}_{e}=0 \\
& m_{\mathrm{W}} \mathrm{C}_{\mathrm{P}, \mathrm{W}} \frac{d \mathrm{~T}_{\mathrm{W}}}{d \mathrm{t}}-\mathrm{Q}_{e}=0 \\
& \mathrm{Q}_{p}=-\Delta \mathrm{H}_{\mathrm{r}}\left(r_{\text {film }} \mathrm{V}_{\text {film }}+r_{\text {bulk }} \mathrm{V}_{\text {bulk }}\right) \\
& \mathrm{Q}_{e}=U A\left(\mathrm{~T}_{\mathrm{R}}-\mathrm{T}_{\mathrm{W}}\right)
\end{aligned}
$$

where $m_{i}$ is the mass of component i. $Q_{p}$ an $Q_{e}$ stand for the heat flux produced by the reaction and the heat flux exchanged between the fluid and the wall. $T_{R}$ and $T_{W}$ correspond to the reactive medium and the wall temperatures.

4.3.2.3. Initial conditions. The initial temperatures of the wall and the fluid are the temperature at normal operating conditions, i.e. $30^{\circ} \mathrm{C}$. The initial molar composition for each phase is given in Table 6. It is considered homogeneous between the film and the bulk.

\subsubsection{Simulation results}

The scenarios described in Section 4.3.1 are simulated. The failures start at $t=0$.

\section{- Semi-batch process:}

At $t<0$ : the reactor is initially filled with toluene. The acid mixture is introduced while there is NO stirring. The reaction is very slow and the conversion rate is close to zero because the interfacial area is low. The failure starts after the end of the dosing.

At $t=0$ : stirring is restarted but there is no flow rate of the cooling fluid. The reactor is simulated as a pure batch reactor filled with both reactants.

\section{- Continuous process:}

At $t<0$ : normal operating conditions are considered.

At $t=0$ : the fluids circulation is stopped (both utility and process fluids). Without any flow, the reactor is considered as a pure batch reactor. It is assumed that the concentration of reactants and products in the reactor at $t=0$ corresponds to the inlet concentrations. This hypothesis overestimates the heat produced during the failure since the reactants in the reactor would have been partly consumed during normal operation before the failure occurs.

Fig. 5 presents the evolution of the fluid temperature in the semi-batch and the HEX reactor. It appears that the temperature in the semi-batch process overcomes the decomposition temperature of nitric acid (i.e. $120^{\circ} \mathrm{C}$ ) in less than $1 \mathrm{~min}$ while the maximal temperature reached in the continuous process is about $86^{\circ} \mathrm{C}$. The heat absorption capacity of the reactor wall $\left(m_{W} C_{P, W}\right)$ represents $11 \%$ of the total heat absorption capacity $\left(m_{W} C_{P, W}+m_{R} C_{P, R}\right)$ for the first process versus $77 \%$ for the second one: it leads to temperatures at equilibrium of about $135^{\circ} \mathrm{C}$ in the semi-batch reactor and $55^{\circ} \mathrm{C}$ in the HEX reactor. Note that the objective is to compare the evolution of the synthesis reaction in both reactors during the failure scenarios. That is why the decomposition reaction occurring from $120^{\circ} \mathrm{C}$ is not taken into account.

Fig. 5 can be related to Fig. 6 which represents the heat flux produced by the reaction $Q_{p}$ and the heat flux exchanged between the process fluid and the reactor wall $Q_{e}$. The ratio between both fluxes is about six times higher in the semibatch reactor $\left(Q_{p} / Q_{e} \sim 1500\right.$ at $t=0.1 \mathrm{~s} ; Q_{p} / Q_{e} \sim 10.4$ at $\left.t=20 \mathrm{~s}\right)$ than in the intensified HEX reactor $\left(Q_{p} / Q_{e} \sim 250\right.$ at $t=0.1 \mathrm{~s}$; $\mathrm{Q}_{p} / \mathrm{Q}_{e} \sim 1.2$ at $t=20 \mathrm{~s}$ ) despite unfavorable conditions for the continuous process (low exchange area and total mass of reactor and high $k_{\mathrm{L}} a$ coefficient) and favorable conditions for the semi-batch process (high heat exchange coefficient and low $k_{L} a$ coefficient). The heat produced is related to the reactor volume. The semi-batch reactor is around 200 times higher than the HEX reactor volume (see Table 5). It is consistent with the observed difference between the initial heat productions. The transitions in the reaction regime for both processes are
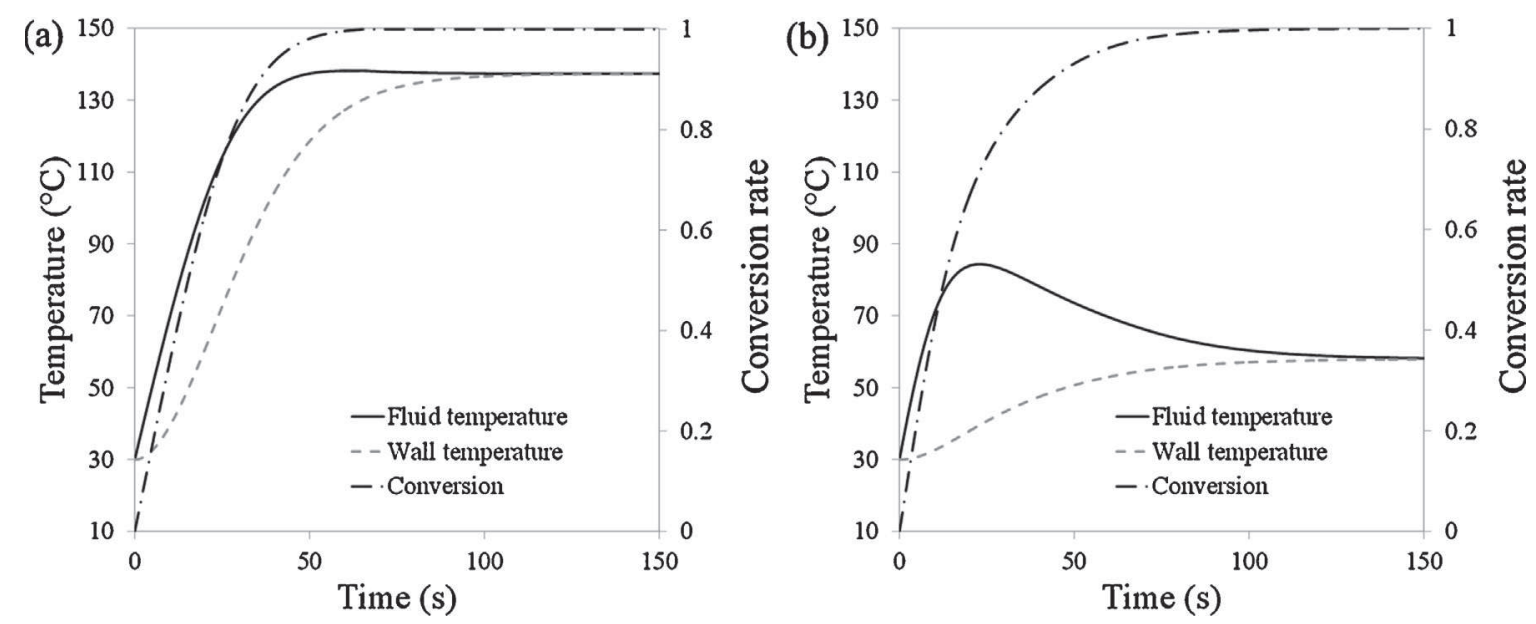

Fig. 5 - Temperature and conversion rate profiles in (a) the semi-batch reactor and (b) the HEX reactor in case of major failure. 

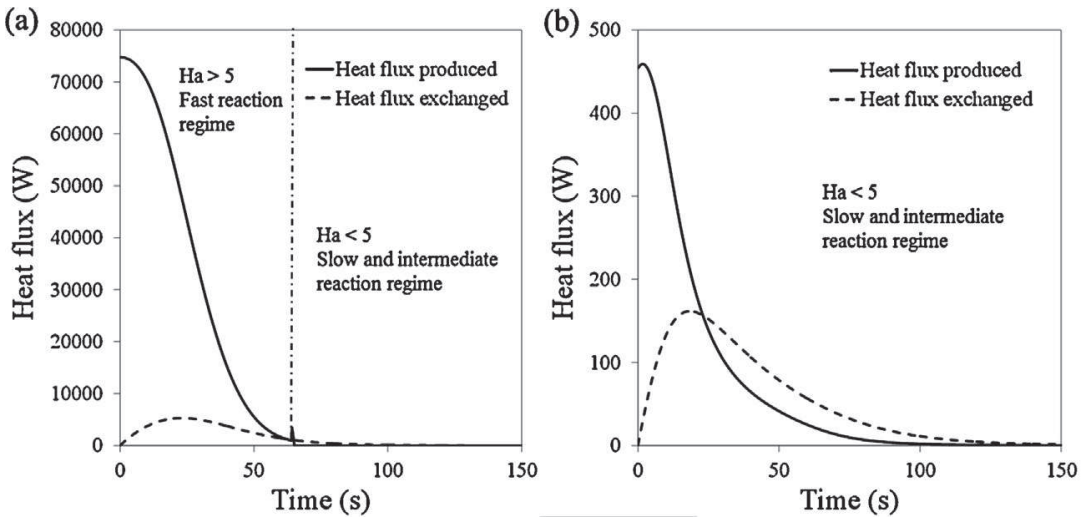

Fig. 6 - Heat flux produced by the reaction and transferred to the reactor wall versus time in (a) the semi-batch reactor and (b) the HEX reactor.

mentioned in Fig. 6. It appears that unlike the HEX reactor, the semi-batch reactor is firstly in a fast reaction regime, where the reaction is monitored by the mass transfer kinetic (see Table 5: $k_{L} a=0.024 \mathrm{~s}^{-1}$ in the semi-batch process $-k_{L} a=1.2 \mathrm{~s}^{-1}$ in the continuous process). The discontinuity observed in Fig. $6(\mathrm{a})$ at about $t=60 \mathrm{~s}$ is due to the transition in the reaction regime from fast with second-order reaction model to intermediate with pseudo-first order model (Appendix A). For $t>65 \mathrm{~s}$ in the semi-batch reactor, $Q_{p}$ is zero because total conversion rate is reached.

Hence, these simulations highlight the potential safety improvements in the implementation of the nitration of toluene when operated in a continuous process (reaction carried out in a millistructured HEX reactor) instead of a semibatch process. The temperature rise in case of failure is better controlled in the intensified device thanks to a good dissipation of the heat produced by the reaction in the reactor wall. This can be explained by the ratio between the mass of the reactor wall and the volume of the reactive medium which is $0.5 \mathrm{~kg} \mathrm{~L}^{-1}$ for the semi-batch reactor and $12.6 \mathrm{~kg} \mathrm{~L}^{-1}$ for the HEX reactor regarding Table 5 .

\subsubsection{Experimental results}

To complete the theoretical study based on simulations, experiments are carried out to investigate the behavior of the intensified SiC HEX reactor in faulty mode. The nitration of toluene is carried out under normal operating conditions (see Section 3.3) at $28^{\circ} \mathrm{C}$ with an input acid strength of $80 \%$ until voluntary failures are caused on the utility fluid line while the process fluid circulates normally. Two failures are studied: (i) LESS utility flow rate by decreasing it from $80 \mathrm{~L} \mathrm{~h}^{-1}$ to $20 \mathrm{~L} \mathrm{~h}^{-1}$ followed by (ii) NO utility flow rate. Fig. 7 presents the evolution of the temperature of the process fluid all along the reactor during the failures. It appears that the temperatures stabilize $300 \mathrm{~s}$ after the utility flow rate reduction. The mean temperature in the reactor has increased of about $1^{\circ} \mathrm{C}$. During normal conditions, the reactor temperature is controlled by the utility temperature, around $28^{\circ} \mathrm{C}$. This temperature is almost constant because of high flow rate condition. The temperature at the inlet of the reactor TI1 is slightly higher because the kinetic rate is maximal due to high concentrations of the reactants (hot spot).

With LESS utility flow rate ( $t=4450 \mathrm{~s}$ in Fig. 7 ), TI1 does not change because the reactants concentrations and the inlet temperature of the utility fluid are still the same. However, since the utility flow rate is lower, its temperature is no longer constant and increases all along the reactor. It explains why TI6 $<$ TI13

In the case of the second failure ( $t=5050 \mathrm{~s}$ in Fig. 7$)$, the temperature in the reactor is no longer controlled by the temperature of the utility fluid. TI1 is the lowest one because the process fluid enters the reactor at room temperature. Then, the temperature increases because of the reaction. It appears that the temperature decreases at the reactor end (TI13<TI6) because the reactant concentration is lower and the heat released by the reaction is dissipated in the reactor mass (Benaissa et al., 2008). The temperature of the process fluid progressively increases because the heat produced is no longer evacuated by the utility fluid. Therefore, the reactor walls and the stagnant utility fluid continuously warm up. However, the temperature rise is slow, of about $0.4^{\circ} \mathrm{C} \mathrm{min}^{-1}$. Considering this value, the critical temperature of $120^{\circ} \mathrm{C}$ would be reached in more than $3 \mathrm{~h} 30$ assuming a constant rate of temperature rise. Moreover, this experiment shows that the temperature decrease is very fast in case of return to normal conditions, with an initial rate of $-10^{\circ} \mathrm{C} \mathrm{min}^{-1}$.

The temperature rise obtained in the continuous process while the utility flow rate is stopped can be compared to the temperature rise estimated in the fed batch reactor in case of similar failure. For that purpose a simulation is carried out assuming NO utility flow rate and NORMAL operating conditions on process side in the semi-batch process. The reactor is initially filled with toluene and the acid mix is fed during $3 \mathrm{~h}$ with a flow rate of $1.4 \mathrm{~L} \mathrm{~h}^{-1}$. The configuration is described in Table 4 but with an initial volume $V_{R}$ of $2.8 \mathrm{~L}$ (initial height

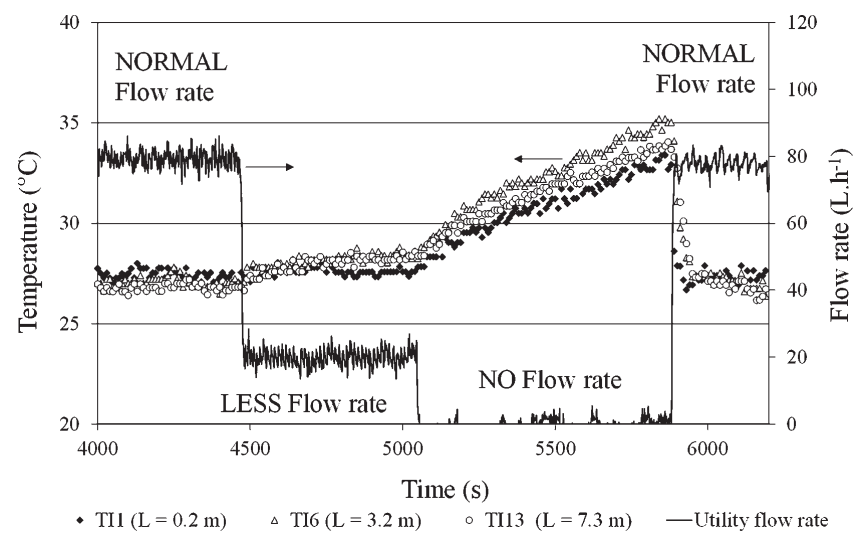

Fig. 7 - Experiment in the continuous process: evolution of the temperature of the process fluid in faulty modes (LESS and NO utility flow rate). 


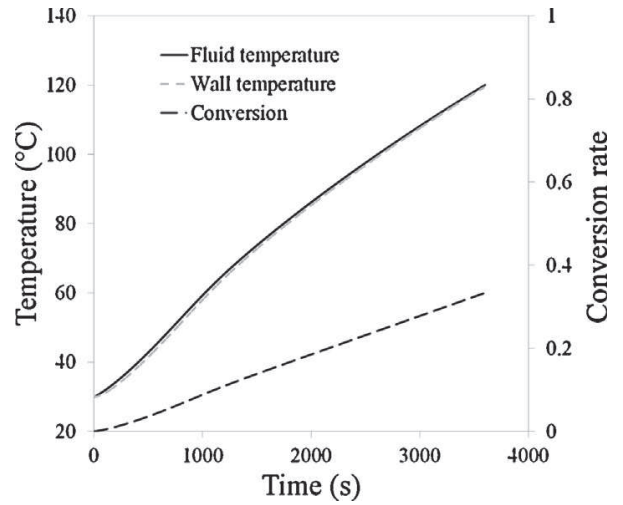

Fig. 8 - Simulation result in the fed-batch process: temperature rise and conversion rate profile in the reactor in case of faulty mode (NO utility flow rate).

$h_{R}=0.08 \mathrm{~m}$ ). The exchange area and the specific area increase during feeding as the volume of the aqueous phase in the reactor increases. The mathematical modeling is described in Section 4.3.2. Eqs. (14), (16) and (18) are replaced by Eqs. (30)-(32) to take into account the acid mix feeding in the material balances.

$\frac{d n_{\mathrm{HNO}_{3}}^{a}}{d t}=-r_{\text {film }} V_{\text {film }}-r_{\text {bulk }} V_{\text {bulk }}+F_{\mathrm{HNO}_{3}}^{0}$

$\frac{d n_{\mathrm{H}_{2} \mathrm{O}}^{a}}{d t}=r_{\text {film }} \mathrm{V}_{\text {film }}+r_{\text {bulk }} \mathrm{V}_{\text {bulk }}+F_{\mathrm{H}_{2} \mathrm{O}}^{0}$

$\frac{d n_{\mathrm{H}_{2} \mathrm{SO}_{4}}^{a}}{d t}=\mathrm{F}_{\mathrm{H}_{2} \mathrm{SO}_{4}}^{0}$

The simulation shows that the reactor temperature reaches $120^{\circ} \mathrm{C}$ in about $1 \mathrm{~h}$ (Fig. 8). It gives a mean rate of temperature rise of $1.5^{\circ} \mathrm{C} \mathrm{min}^{-1}$. It is three times higher than the rate observed in the experiment considering the continuous process.

\section{Conclusion}

This work demonstrates the feasibility of handling highly exothermic reactions in a continuous process instead of a fedbatch process. It is illustrated using the nitration of toluene. This reaction presents a high risk of thermal runaway because of nitric acid decomposition which starts at $120^{\circ} \mathrm{C}$. The device used in the continuous process is a millistructured HEX reactor made of SiC. Conversion rates up to $30 \%$ are reached under typical operating conditions but with low residence times, about $1 \mathrm{~min}$.

This study is completed by a safety analysis. An enhancement in the temperature control in case of failure is observed when using the intensified continuous process instead of the semi-batch reactor. This analysis is performed by simulating major failures for both scenarios identified by a prior risk assessment based on HAZOP method. Unfavorable parameters in terms of mass transfer and heat transfer are considered for the continuous process. However, the simulation work shows that despite high heat production, dissipation in the reactor material enables a reasonable temperature rise of the reactive medium in the continuous process compared to the semi-batch reactor. This tendency is confirmed with an experiment in faulty mode carried out in the SiC HEX reactor.

In order to simulate the continuous process more accurately, it is now necessary to precisely characterize the intensified HEX reactor in terms of mass and heat transfers. The further work under progress is now to develop correlations for the estimation of the mass transfer coefficient and the heat transfer coefficient in function of the operating conditions. Their implementation in steady state and dynamic simulators will provide a robust tool for risk analysis.

\section{Acknowledgments}

This work has been supported by the ANR (Agence Nationale de la Recherche), France: Project ANR PropreSur, ANR-06BLAN-0381-02. The experimental facility was supported by: the FNADT, Grand Toulouse, Prefecture Midi-Pyrenees and FEDER fundings.

\section{Appendix A. Determination of the reaction regime}

To evaluate the impact of mass transfer on the reaction, Hatta number is calculated to determine the reaction regime (slow, fast or intermediate) as described by Trambouze and Euzen (2002) and Levenspiel (1999):

$\mathrm{Ha}=\frac{\sqrt{\mathrm{KC}_{\mathrm{HNO}_{3}}^{a} D_{\mathrm{tol}}^{a}}}{k_{\mathrm{L}}}$

$\mathrm{K}$ is the intrinsic kinetic constant obtained from the model proposed by Zaldivar et al. (1995). $\mathrm{C}_{\mathrm{HNO}_{3}}^{a}$ is the nitric acid concentration in aqueous phase.

\section{A.1. Slow and intermediate reaction regime: $\mathrm{Ha}<5$}

In slow and intermediate reaction regime $(\mathrm{Ha}<5)$, it is assumed that this concentration is homogeneous in the whole aqueous phase (in the film and in the bulk) because of fast transfer to the film and large excess compared to toluene. To validate this hypothesis, it is possible to calculate the factor $\mathrm{N}_{2}$ :

$N_{2}=\frac{D_{\mathrm{HNO}_{3}}^{a} C_{\mathrm{HNO}_{3}}^{a}}{D_{\text {tol }}^{a} C_{\text {tol }}^{a, i}}$

$C_{\text {tol }}^{a, i}$ is the concentration of toluene in aqueous phase at the interface. In the simulations, $\mathrm{N}_{2}$ is greater than 10 up to a conversion rate of $97 \%$. Therefore this assumption has low impact on the calculation of the heat produced by the reaction as a function of time. However it allows to consider the reaction as a pseudo-first order reaction when $\mathrm{Ha}<5$. With this simplified approach, analytical solutions exist to describe the reactants consumption (Trambouze and Euzen, 2002).

Assuming pseudo-first order reaction, the concentration in the bulk and the enhancement factor are obtained from the following equations:

$$
\begin{aligned}
& N_{3}=\frac{1}{\operatorname{ch}(\mathrm{Ha} a} \cdot \frac{1}{1+\mathrm{Ha}\left(\frac{\varepsilon_{\mathrm{aq}} k_{\mathrm{L}}}{a D_{\mathrm{tol}}^{a}}-1\right) \operatorname{th}(\mathrm{H} a)} \\
& C_{\text {tol }}^{a, b}=N_{3} C_{\text {tol }}^{a, i} \\
& E=\frac{\mathrm{H} a}{\operatorname{th}(\mathrm{Ha} a} \cdot \frac{1-\left(N_{3} / \operatorname{ch}(\mathrm{Ha})\right)}{1-N_{3}}
\end{aligned}
$$

For $\mathrm{Ha}<0.02, \mathrm{~N}_{3}=1$. 


\section{A.2. Fast reaction regime: $\mathrm{Ha}>5$}

The reaction in the film is so fast that $C_{\text {tol }}^{a, b}=0$. Moreover nitric acid transfer can be limiting. Two tendencies can be observed: (i) if $\mathrm{Ha} / \mathrm{N}_{2}<0.1, E=\mathrm{Ha}$; (ii) if $\mathrm{Ha} / \mathrm{N}_{2}>10, E=1+\mathrm{N}_{2}$. Kishinevskii proposed an explicit correlation to estimate the enhancement factor in fast reaction regime for second order reaction (Trambouze and Euzen, 2002):

$$
\begin{aligned}
& E=1+\frac{H a}{N_{4}}\left(1-\exp \left(-0.65 H a \sqrt{N_{4}}\right)\right) \\
& N_{4}=\frac{H a}{N_{2}}+\exp \left(\frac{0.68}{H a}-\frac{0.45 H a}{N_{2}}\right)
\end{aligned}
$$

\section{References}

Anxionnaz, Z., Cabassud, M., Gourdon, C., Tochon, P., 2008. Heat exchanger/reactors (HEX reactors): concepts, technologies: state-of-the-art. Chem. Eng. Process.: Process Intensif. 47, 2029-2050.

Anxionnaz, Z., Cabassud, M., Gourdon, C., Tochon, P., 2013. Influence of the meandering channel geometry on the thermo-hydraulic performances of an intensified heat exchanger/reactor. Chem. Eng. Process.: Process Intensif. 73, 67-80.

Benaissa, W., Elgue, S., Gabas, N., Cabassud, M., Carson, D., Demissy, M., 2008. Dynamic behaviour of a continuous heat exchanger/reactor after flow failure. Int. J. Chem. React. Eng 6, A23.

Booth, G., 2000. Nitro compounds, aromatic. In: Ullmann's Encyclopedia of Industrial Chemistry. John Wiley \& Sons, Weinheim.

Burns, J.R., Ramshaw, C., 2002. A microreactor for the nitration of benzene and toluene. Chem. Eng. Commun. 189, 1611-1628.

Chandratilleke, T.T., 2003. Numerical prediction of secondary flow and convective heat transfer in externally heated curved rectangular ducts. Int. J. Therm. Sci. 42, 187-198.

Chen, C.Y., Wu, C.W., 1996. Thermal hazard assessment and macrokinetics analysis of toluene mononitration in a batch reactor. J. Loss Prev. Process Ind. 9, 309-316.

D’Angelo, F.A., Brunet, L., Cognet, P., Cabassud, M., 2003. Modelling and constraint optimisation of an aromatic nitration in liquid-liquid medium. Chem. Eng. J. 91, 75-84.

Despènes, L., Elgue, S., Gourdon, C., Cabassud, M., 2012. Impact of the material on the thermal behavior of heat exchangersreactors. Chem. Eng. Process.: Process Intensif. 52, 102-111.

Di Miceli Raimondi, N., Olivier-Maget, N., Elgue, S., Gabas, N., Cabassud, M., 2009. Evaluation des risques par la méthode HAZOP d'un réacteur semi-batch et d'un réacteur-échangeur continu. Récents Progrès en Génie des Procédés 98 (Article 585).

Dugal, M., 2005. Nitrobenzene and nitrotoluenes. In: Kirk-Othmer Encyclopedia of Chemical Technology. John Wiley \& Sons Inc., New York.

Dunjo, J., Fthenakis, V., Vilchez, J.A., Arnaldos, J., 2010. Hazard and operability (HAZOP) analysis. A literature review. J. Hazard. Mater. 173, 19-32.

Ebrahimi, F., Virkki-Hatakka, T., Turunen, I., 2012. Safety analysis of intensified processes. Chem. Eng. Process. 52, 28-33.

Elgue, S., Conte, A., Gourdon, C., Bastard, Y., 2012. Direct fluorination of 1,3-dicarbonyl compound in a continuous flow reactor at industrial scale. Chem. Today 30, 18-21.

Fellouah, H., Castelain, C., Ould el Moctar, A., Peerhossaini, H., 2006. A criterion for detection of the onset of Dean instability in Newtonian fluids. Eur. J. Mech. B: Fluids 25, 505-531.
Fernandes, J.B., Sharma, M.M., 1967. Effective interfacial area in agitated liquid-liquid contactors. Chem. Eng. Sci. 22, 1267-1282.

Franck, H.G., Stadelhofer, J.W., 1987. Production and uses of toluene derivatives. In: Industrial Aromatic Chemistry. Springer-Verlag, Berlin Heidelberg.

Ghaini, A., Kashid, M.N., Agar, D.W., 2010. Effective interfacial area for mass transfer in the liquid-liquid slug flow capillary microreactors. Chem. Eng. Process. 49, 358-366.

Garstecki, P., Fuerstman, M.J., Stone, H.A., Whitesides, G.M., 2006. Formation of droplets and bubbles in a microfluidic T-junction - scaling and mechanism of break-up. Lab Chip 6, 437-446.

Gupta, R., Leung, S.S.Y., Manica, R., Fletcher, D.F., Haynes, B.S., 2013. Hydrodynamics of liquid-liquid Taylor flow in microchannels. Chem. Eng. Sci. 92, 180-189.

Halder, R., Lawal, A., Damavarapu, R., 2007. Nitration of toluene in a microreactor. Catal. Today 125, 74-80.

Harris, G.F.P., 1976. Isomer control in the mononitration of toluene. In: Industrial and Laboratory Nitration. ACS Symposium Series, vol. 22. American Chemical Society, Washington, pp. 300-312.

Haynes, W.M., (Internet Version 2013) 2013. CRC Handbook of Chemistry and Physics, 93rd ed. CRC Press/Taylor \& Francis, Boca Raton.

Henke, L., Winterbauer, H., 2005. A modular microreactor for mixed acid nitration. Chem. Eng. Technol. 28, 749-752.

Jiang, F., Drese, K.S., Hardt, S., Kûpper, M., Schönfeld, F., 2004. Helical flows and chaotic mixing in curved micro channels. AIChE J. 50, 2297-2305.

Joseph, B., Smith, E.P., Adler, R.J., 1975. Numerical treatment of laminar flow in helically coiled tubes of square cross section. AIChE J. 21, 965-974.

Levenspiel, O., 1999. Fluid-fluid reactions: kinetics. In: Chemical Reaction Engineering, 3rd ed. John Wiley \& Sons, New York.

Ligrani, P.M., Niver, R.D., 1988. Flow visualization of dean vortices in a curved channel with 40 to 1 aspect ratio. Phys. Fluids 31, 3605-3617.

Molga, E.J., Barcons, C., Zaldivar, J.M., 1993. Mononitration of toluene and quantitative determination of the isomer distribution by gas chromatography. Afinidad 50, 15-20.

Miller, R.C., Noyce, D.S., Vermeulen, T., 1964. The kinetics of aromatic nitration. Ind. Eng. Chem. 56, 43-53.

NIST (National Institute of Standards and Technology), 2013. WebBook of Chemistry. http://webbook.nist.gov/chemistry/

Rush, T.A., Newell, T.A., Jacobi, A.M., 1999. An experimental study of flow and heat transfer in sinusoidal wavy passages. Int. J. Heat Mass Transf. 42, 1541-1553.

Rusli, R., Shariff, A.M., Khan, F.I., 2013. Evaluating hazard conflicts using inherently safer design concept. Saf. Sci. 53, 61-72.

Stoessel, F., 2008. Thermal Safety of Chemical Processes: Risk Assessment and Process Design. Wiley, Weinheim.

Townsend, D.I., Tou, J.C., 1980. Thermal hazard evaluation by an accelerating rate calorimeter. Thermochim. Acta 37, $1-30$.

Trambouze, P., Euzen, J.P., 2002. Les réacteurs chimiques, de la conception à la mise en œuvre. Technip, Paris.

Yeh, H.S., Wills, G.B., 1971. Diffusion coefficient of aqueous nitric acid at $25^{\circ} \mathrm{C}$ as function of concentration from 0.1 to $1.0 \mathrm{M}$. J. Chem. Eng. Data 16, 76-77.

Zaldivar, J.M., Molga, E., Alos, M.A., Hernandez, H., Westerterp, K.R., 1995. Aromatic nitrations by mixed acid. Slow liquid-liquid reaction regime. Chem. Eng. Process. 34, 543-559.

Zaldivar, J.M., Molga, E., Alos, M.A., Hernandez, H., Westerterp, K.R., 1996. Aromatic nitrations by mixed acid. Fast liquid-liquid reaction regime. Chem. Eng. Process. 35, 91-105. 